\title{
Three-dimensional versus two-dimensional laparoscopy for ovarian cystectomy: a prospective randomised study
}

\author{
MW Lui *, Vincent YT Cheung
}

\section{A B S T R A C T}

Introduction: Three-dimensional (3D) laparoscopy is now available as an alternative to conventional two-dimensional (2D) laparoscopy for ovarian cystectomy. However, the clinical value of 3D laparoscopy in benign gynaecological surgery remains uncertain. This study evaluated whether 3D laparoscopy had any advantages over 2D laparoscopy for ovarian cystectomy for apparently benign ovarian cysts.

Methods: This prospective randomised study involved patients undergoing laparoscopic ovarian cystectomy. The primary outcomes were the duration of cystectomy and surgeon's Global Operative Assessment of Laparoscopic Skills (GOALS) score. The secondary outcomes were the preferences, perceptions, and adverse effects reported by the participating surgeons.

Results: There were 38 patients assigned to the 2D laparoscopy group and 37 patients assigned to the 3D laparoscopy group. Participating surgeons in the $2 \mathrm{D}$ group reported more efficient tissue handling than did those in the $3 \mathrm{D}$ group (mean [standard deviation] rating score, 4.2 [0.8] vs 3.8 [0.8]; $\mathrm{P}=0.033)$. Duration of cystectomy (47.6 [32.0] min vs 51.6 [36.2] $\mathrm{min} ; \mathrm{P}=0.198)$ and overall GOALS score (20.8 [3.9] vs 20.1 [3.3]; $\mathrm{P}=0.393$ ) were similar between both groups. Participating surgeons in the 2D group reported nausea, dizziness, ocular fatigue, and blurring of vision less frequently than did those in the $3 \mathrm{D}$ group $(5.3 \%$ vs $45.9 \%$; $\mathrm{P}<0.001)$.

Conclusion: There were no significant benefits to using 3D laparoscopy compared with conventional 2D laparoscopy for ovarian cystectomy, and 3D laparoscopy may cause more frequent adverse effects in surgeons.

Hong Kong Med J 2018;24:245-51

DOI: $10.12809 / \mathrm{hkmj} 176846$

MW Lui *, MB, BS, MRCOG

VYT Cheung, MB, BS, FRCOG

Department of Obstetrics and Gynaecology, Queen Mary Hospital, The University of Hong Kong, Pokfulam, Hong Kong

* Corresponding author: luimanwa@gmail.com

New knowledge added by this study

- For ovarian cystectomy, there is no significant benefit to using three-dimensional laparoscopy rather than conventional two-dimensional laparoscopy.

- Three-dimensional laparoscopy permits binocular vision and depth perception; however, surgeons using threedimensional laparoscopy more frequently reported adverse effects such as ocular fatigue, nausea, dizziness, and blurring of vision.

Implications for clinical practice or policy

- Clinical use of three-dimensional laparoscopy in more complex surgical procedures, such as laparoscopic suturing, or with more experienced surgeons may be beneficial; therefore, further investigation is worthwhile.

\section{Introduction}

Laparoscopy has replaced laparotomy in most gynaecological procedures, and laparoscopic cystectomy is currently the mainstay of treatment for apparently benign ovarian cysts. However, the absence of depth perception and limited instrument dexterity are major drawbacks of laparoscopy. Advances in three-dimensional (3D) video imaging technology allow 3D laparoscopy to provide better precision than conventional two-dimensional (2D) laparoscopy, especially in depth perception and spatial orientation. This increased precision may help improve surgeon's performance during laparoscopic surgery.

Studies have shown that 3D laparoscopy objectively ${ }^{1,2}$ and subjectively ${ }^{3,4}$ improves surgical performance, especially during complex tasks. ${ }^{5}$ In addition, 3D laparoscopy lessens the learning curve for beginners. ${ }^{6}$ The durations of laparoscopic cholecystectomy and pelvic lymphadenectomy have also been shortened when performed using 3D technologies. ${ }^{7,8}$ However, the clinical value of 3D laparoscopy in benign gynaecological surgery remains uncertain. This study aimed to evaluate any advantages of using 3D laparoscopy over 2D laparoscopy for ovarian cystectomy. 


\section{三維與二維腹腔鏡卵巢囊腫切除術：前瞻性 隨機研究 \\ 雷雯華、張煜棠}

引言 : 三維 $(3 \mathrm{D})$ 腹腔鏡可替代傳統的二維 $(2 \mathrm{D})$ 腹腔鏡手術進行 卵巢囊腫切除術。然而, 3D腹腔鏡在良性婦科手術中的臨床價值仍不 確定。本研究評估3D腹腔鏡與2D腹腔鏡檢查相比對於明顯良性卵巢 囊腫切除術是否有優勢。

方法：這項前瞻性隨機研究涉及接受腹腔鏡卵巢囊腫切除術的患者。 主要研究結果是卵巢囊腫切除術的手術時間和外科醫生的整體腹腔鏡 技術 (GOALS) 評分。次要結果是參與研究的外科醫生報告的偏好 認知和不良反應。

結果：38例患者分配到 $2 \mathrm{D}$ 腹腔鏡組, 37 例患者分配到 $3 \mathrm{D}$ 腹腔鏡 組。2D組的參與外科醫生相比3D組報告更有效的組織處理（平均 〔標準差〕評分：4.2〔0.8〕比3.8〔0.8〕； $\mathrm{P}=0.033) 。$ 兩組患者 的手術時間 ( $47.6 〔 32.0 〕$ 分鐘比51.6〔36.2〕分鐘 $; \mathrm{P}=0.198)$ 和 GOALS總評分（20.8〔3.9〕比20.1〔3.3〕; $\mathrm{P}=0.393$ ) 相若。2D 組的參與外科醫生報告噁心、頭量、眼疲勞和視力模糊較 $3 \mathrm{D}$ 組為低 ( $5.3 \%$ 比 $45.9 \% ; \mathrm{P}<0.001)$ 。

結論：與常規2D腹腔鏡手術相比, 使用3D腹腔鏡手術對於卵巢囊腫 切除術沒有明顯益處。3D腹腔鏡手術可能會對外科醫生造成更多不良 反應。 access. For 3D laparoscopy, a 10-mm 3D telescopic videoscope was used (Endoeye Flex 3D; Olympus, Center Valley [PA], US). All surgeons were trained for 3D laparoscopy using a pelvic trainer with standardised tasks including peg transfer, precision cutting, duct cannulation, and suturing with knot tying. The 3D laparoscopy training was continued until the surgeons could confidently operate using 3D images. All non-specialist surgeons were supervised by a laparoscopist accredited at the advanced level in gynaecological laparoscopic surgery, according to the Hong Kong College of Obstetricians and Gynaecologists. ${ }^{9}$ At their discretion, surgeons were allowed to switch from 3D laparoscopy to traditional 2D laparoscopy if difficulty was encountered during surgery. All 2D laparoscopies were performed using a 10-mm laparoscope (26033AP; Karl Storz Endoscopy-America Inc, Culver City [CA], US). The same 32-inch high-definition monitor (LMD3215MT; Sony Corporation, Tokyo, Japan) was used for all operations. In the 2D and 3D groups, cystectomy was performed in the usual manner, using two or three 5-mm accessory ports inserted in the lower abdomen under direct vision. The start time of the operation (first skin incision), insertion of primary trocar, completion of cystectomy, and end of operation (final skin closure) were recorded by the research nurse.

After the operation, all surgeons were required to self-evaluate their performance by using the Global Operative Assessment of Laparoscopic Skills (GOALS) assessment tool. ${ }^{10}$ The five-item GOALS score includes assessment of depth perception, bimanual dexterity, efficiency, tissue handling, and autonomy. Any operator discomfort encountered during the surgery, any need to convert to $2 \mathrm{D}$ laparoscopy, and the surgeon's preference for the type of laparoscopy based on experience were also recorded. Demographic data and operative findings, such as size and laterality of cysts, operative duration, and presence of adhesions were analysed. Duration of cystectomy was defined as the time from completion of primary port insertion to separation of the cyst from the ovary and completion of haemostasis. The time spent on specimen retrieval was not included, owing to variations in the specimen retrieval method with or without use of a specimen bag.

The primary outcome of the present study was the difference between the GOALS score of 2D and $3 \mathrm{D}$ groups. The secondary outcomes were the duration of cystectomy and surgeon's preferences and reported adverse effects. Subgroup analysis was performed to compare the outcomes for different experience levels among the surgeons. The surgeons were categorised according to their experience in performing laparoscopic surgery ( $\leq 5$ years or $>5$ years). Surgeons with more than 5 years of experience had achieved competency in 
gynaecological laparoscopic surgery to at least an intermediate level, according to the Hong Kong College of Obstetricians and Gynaecologists, and had completed a required number of laparoscopic operations as requested by the College. ${ }^{9}$

A sample size of 36 patients was required in each group, as calculated using an alpha of 0.05 and a beta of 0.2 for detection of a difference in the sum of four items of the GOALS score (excluding tissue handling) of 13 (interquartile range [IQR], 11-16) in the $2 \mathrm{D}$ group and 16 (IQR, 12-18) in the 3D group, as based on a previous study, ${ }^{11}$ using a two-sided test. To allow for a $10 \%$ dropout rate, 40 patients were recruited into each group. For randomised patients whose operations were subsequently rescheduled outside the study period, treatment assignment numbers were reallocated to subsequent eligible patients who provided consent. Statistical analysis was performed using SPSS Windows version 21.0 (IBM Corp, Armonk [NY], US). Data were presented as proportions or mean and standard deviation. Student's $t$ test and Chi squared test were used for statistical analyses. A P value of $<0.05$ was considered statistically significant.

\section{Results}

Of the 83 patients recruited into the study from May 2014 to May 2016, operations were rescheduled for three patients who were therefore withdrawn from the study; 80 patients completed the trial (Fig). Of these 80 patients, two from the $2 \mathrm{D}$ group and three from the $3 \mathrm{D}$ group were excluded from analysis because no cysts were identified. Finally, 38 patients in the 2D group and 37 patients in the $3 \mathrm{D}$ group were included for analysis. Patient characteristics and surgical outcomes are presented in Table 1. There were no significant differences between the $2 \mathrm{D}$ and $3 \mathrm{D}$ groups in terms of patient age, laterality of the ovarian cyst, histological diagnosis of the cyst, presence of severe adhesions, volume of blood loss, and experience level of the surgeon. Three accessory ports were used in four patients in the 2D group and in five patients in the 3D group. In all other patients, two accessory ports were used. The mean (standard deviation) diameter of the ovarian cyst was smaller in the $3 \mathrm{D}$ group than that in the $2 \mathrm{D}$ group (5.1 [2.1] $\mathrm{cm}$ vs $6.1 \mathrm{~cm}[2.1] \mathrm{cm} ; \mathrm{P}=0.031$ ). Body mass index in the $2 \mathrm{D}$ group was significantly higher than that in the $3 \mathrm{D}$ group $\left(23.4\right.$ [4.4] $\mathrm{kg} / \mathrm{m}^{2}$ vs 21.3 [2.6] $\mathrm{kg} / \mathrm{m}^{2}$; $\mathrm{P}=0.011)$. Severe adhesion was defined as a score of $>20$ for adnexal adhesion unilaterally ${ }^{12}$ or a score of $>40$ for endometriosis, ${ }^{13}$ according to the American Society for Reproductive Medicine classifications.

The differences between 2D and 3D groups in terms of GOALS score and duration of cystectomy are presented in Table 2. A total of 15 surgeons participated in the study and there were 13 in each

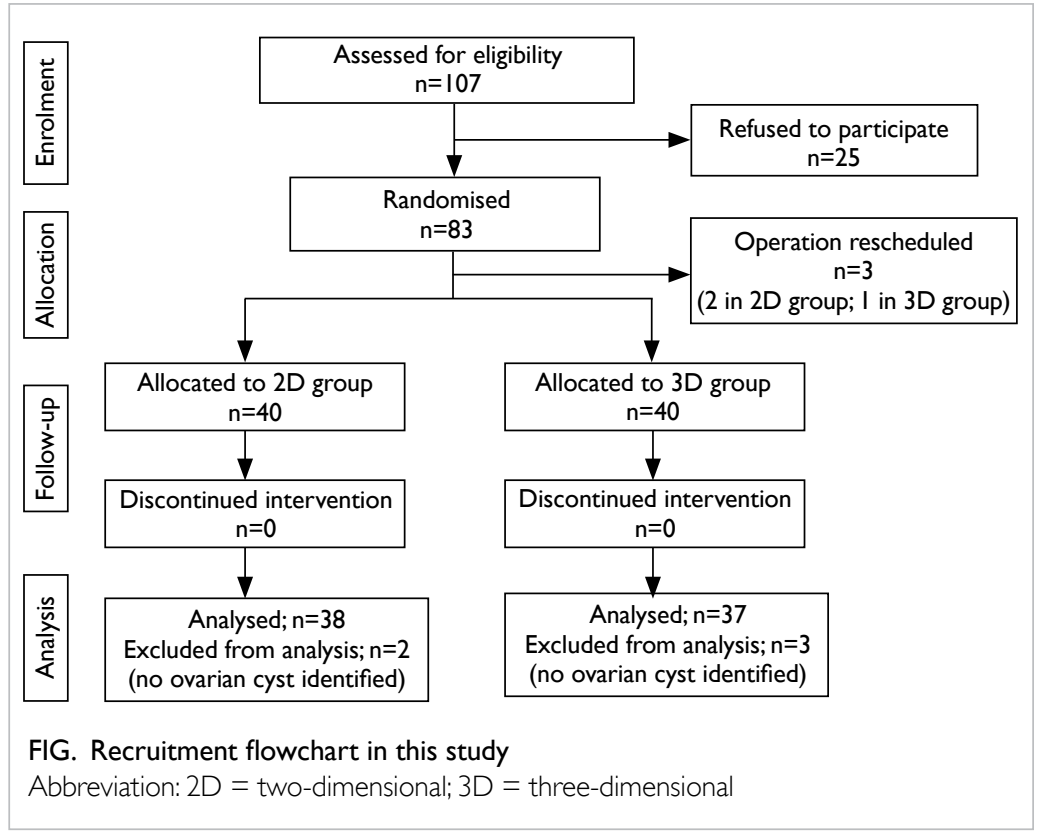

group: 11 in both, while two for each were involved in $2 \mathrm{D}$ and $3 \mathrm{D}$ groups, respectively. Participating surgeons in the $2 \mathrm{D}$ group reported more efficient tissue handling than did those in the $3 \mathrm{D}$ group. Adverse effects, including nausea, dizziness, ocular fatigue, and blurring of vision were reported less frequently by participating surgeons in $2 \mathrm{D}$ group than those in 3D group (Table 3). However, none of the participating surgeons requested intra-operative conversion from $3 \mathrm{D}$ to $2 \mathrm{D}$ laparoscopy. At the end of surgery, more participating surgeons in the 3D group expressed a preference for 2D laparoscopy (43.3\%) than for 3D laparoscopy (18.9\%), whereas $37.8 \%$ had no preference. A subgroup analysis of participating surgeons in the two groups did not show statistically significant differences in terms of GOALS score (2D vs 3D; 28.9 [5.1] vs 28.2 [46.0]; $\mathrm{P}=0.585)$, tissue handling $(4.2[0.8]$ vs $3.9[0.8]$; $\mathrm{P}=0.060)$, and duration of cystectomy (93.7 [46.1] min vs 97.7 [52.2] $\mathrm{min} ; \mathrm{P}=0.737$ ).

Subgroup analyses according to the experience level of the surgeon and the presence of dense adhesions are shown in Tables 4 and 5, respectively. Two of the surgeons in the 3D group and three of the surgeons in the 2D laparoscopy are accredited at the advanced level in gynaecological laparoscopic surgery by the Hong Kong College of Obstetricians and Gynaecologists. Surgeons with more than 5 years of laparoscopic experience reported lower scores in tissue handling and efficiency when using 3D laparoscopy. There were no differences in terms of GOALS score and duration of cystectomy in the subgroup with dense adhesions. 
TABLE I. Patient characteristics and surgical outcomes*

\begin{tabular}{|c|c|c|c|}
\hline & $\begin{array}{l}\text { Two-dimensional group } \\
(n=38)\end{array}$ & $\begin{array}{l}\text { Three-dimensional group } \\
(\mathrm{n}=\mathbf{3 7})\end{array}$ & $P$ value \\
\hline Age, y & $36.6(7.1)$ & $35.6(7.0)$ & 0.538 \\
\hline Body mass index, $\mathrm{kg} / \mathrm{m}^{2}$ & $23.4(4.4)$ & $21.3(2.6)$ & 0.011 \\
\hline Laterality of cysts & & & 0.891 \\
\hline Unilateral & $22(57.9 \%)$ & $22(59.5 \%)$ & \\
\hline Bilateral & $16(42.1 \%)$ & $15(40.5 \%)$ & \\
\hline Size (longest diameter) of cyst, cm & $6.1(2.1)$ & $5.1(2.1)$ & 0.031 \\
\hline Presence of severe adhesions & $14(36.8 \%)$ & $13(35.1 \%)$ & 0.878 \\
\hline Blood loss, mL & $55.1(64.8)$ & $58.2(56.2)$ & 0.825 \\
\hline Duration of hospital stay, $d$ & $2.6(1.2)$ & $2.4(1.3)$ & 0.489 \\
\hline Surgeon's experience & & & 0.725 \\
\hline$\leq 5$ Years & $19(50.0 \%)$ & $17(45.9 \%)$ & \\
\hline$>5$ Years & $19(50.0 \%)$ & $20(54.1 \%)$ & \\
\hline Histology & & & 0.054 \\
\hline Dermoid cyst & $9(23.7 \%)$ & $14(37.8 \%)$ & \\
\hline Endometriotic cyst & $25(65.8 \%)$ & $16(43.2 \%)$ & \\
\hline Others $†$ & $4(10.5 \%)$ & 7 (18.9\%) & \\
\hline
\end{tabular}

* Data are shown as mean (standard deviation) or No. (\%) of subjects

+ Other histologies included five cases of serous cystadenoma, two cases of mucinous cystadenoma, one case of mucinous borderline ovarian tumour, and three cases of follicular cysts

TABLE 2. Differences between the 2D and 3D laparoscopy groups in terms of surgeon's GOALS score and duration of cystectomy*

\begin{tabular}{lccc}
\hline & 2D group $(\mathbf{n}=\mathbf{3 8})$ & 3D group $(\mathbf{n}=\mathbf{3 7})$ & P value \\
\hline Overall GOALS score & $20.8(3.9)$ & $20.1(3.3)$ & 0.393 \\
Component of GOALS score & & & 0.888 \\
$\quad$ Depth perception & $4.1(1.0)$ & $4.1(0.8)$ & 0.782 \\
\hline Bimanual dexterity & $4.1(0.8)$ & $4.1(0.8)$ & 0.503 \\
\hline Efficiency & $4.2(1.0)$ & $4.1(0.7)$ & 0.033 \\
\hline Tissue handling & $4.2(0.8)$ & $3.8(0.8)$ & 0.434 \\
\hline Autonomy & $4.2(0.9)$ & $4.1(0.8)$ & 0.198 \\
\hline Duration of cystectomy, min & $47.6(32.0)$ & $51.6(36.2)$ & \\
\hline
\end{tabular}

Abbreviations: $2 \mathrm{D}$ = two-dimensional; $3 \mathrm{D}$ = three-dimensional; GOALS = Global Operative Assessment of Laparoscopic Skills

* Data are presented as mean (standard deviation)

TABLE 3. Adverse effects reported by participating surgeons

\begin{tabular}{lccc}
\hline & $\begin{array}{c}\text { Two-dimensional } \\
\text { group (n=38) }\end{array}$ & $\begin{array}{c}\text { Three-dimensional } \\
\text { group (n=37) }\end{array}$ & P value \\
\hline No. of operations that surgeons reported adverse effects & $2(5.3 \%)$ & $17 \dagger(45.9 \%)$ & $<0.001$ \\
Nausea & 1 & 8 & \\
Dizziness & 0 & 8 & \\
Ocular fatigue & 1 & 9 \\
Blurring of vision & 0 & 2 & \\
\hline
\end{tabular}

† Some surgeons experienced more than one adverse effect 
TABLE 4. Comparison between the 2D and 3D groups in terms of surgeon's GOALS score and duration of cystectomy according to the experience level of the surgeon*

\begin{tabular}{|c|c|c|c|c|c|c|}
\hline & \multicolumn{3}{|c|}{ Surgeon's experience $\leq 5$ years } & \multicolumn{3}{|c|}{ Surgeon's experience $>5$ years } \\
\hline & $\begin{array}{c}\text { 2D group } \\
(n=19)\end{array}$ & $\begin{array}{l}\text { 3D group } \\
(n=17)\end{array}$ & $P$ value & $\begin{array}{l}\text { 2D group } \\
(n=19)\end{array}$ & $\begin{array}{l}\text { 3D group } \\
(n=20)\end{array}$ & $P$ value \\
\hline Age of patient, $y$ & $34.1(6.8)$ & $36.1(7.4)$ & 0.391 & $39.1(6.7)$ & $35.1(6.9)$ & 0.073 \\
\hline Body mass index, $\mathrm{kg} / \mathrm{m}^{2}$ & $22.7(3.4)$ & $20.9(2.3)$ & 0.068 & $24.2(5.3)$ & $21.5(2.8)$ & 0.065 \\
\hline Size of ovarian cyst, $\mathrm{cm}$ & $6.3(1.9)$ & $5.3(2.2)$ & 0.170 & $6.0(2.3)$ & $4.8(2.1)$ & 0.116 \\
\hline Bilateral cysts & $9(47.4 \%)$ & $9(52.9 \%)$ & 0.738 & $7(36.8 \%)$ & $6(30.0 \%)$ & 0.651 \\
\hline Presence of severe adhesions & $7(36.8 \%)$ & $7(41.2 \%)$ & 0.790 & $7(36.8 \%)$ & $6(30.0 \%)$ & 0.651 \\
\hline Blood loss, $\mathrm{mL}$ & $64.0(64.3)$ & $72.9(60.5)$ & 0.668 & $46.3(65.7)$ & $45.8(0.4)$ & 0.976 \\
\hline Overall GOALS score & $18.9(3.5)$ & $18.2(3.1)$ & 0.551 & $22.8(3.2)$ & $21.8(2.5)$ & 0.268 \\
\hline Depth perception & $3.8(0.9)$ & $3.7(0.8)$ & 0.768 & $4.4(1.0)$ & $4.5(0.6)$ & 0.764 \\
\hline Bimanual dexterity & $3.7(0.7)$ & $3.7(0.8)$ & 0.726 & $4.5(0.6)$ & $4.5(0.6)$ & 0.698 \\
\hline Efficiency & $3.7(1.0)$ & $3.8(0.7)$ & 0.634 & $4.7(0.6)$ & $4.2(0.6)$ & 0.033 \\
\hline Tissue handling & $3.9(0.7)$ & $3.5(0.8)$ & 0.165 & $4.6(0.6)$ & $4.1(0.8)$ & 0.040 \\
\hline Autonomy & $3.8(0.9)$ & $3.5(0.5)$ & 0.272 & $4.6(0.8)$ & $4.5(0.8)$ & 0.593 \\
\hline Duration of cystectomy, min & $60.7(37.7)$ & $64.7(39.0)$ & 0.756 & $34.5(18.0)$ & $40.5(30.3)$ & 0.457 \\
\hline Presence of adverse effects & $2(10.5 \%)$ & $8(47.1 \%)$ & 0.015 & 0 & $9(45.0 \%)$ & 0.001 \\
\hline
\end{tabular}

Abbreviations: 2D = two-dimensional; 3D = three-dimensional; GOALS = Global Operative Assessment of Laparoscopic Skills

* Data are shown as mean (standard deviation) or No. (\%) of subjects

TABLE 5. Comparison between the 2D and 3D groups in terms of surgeon's GOALS score and duration of cystectomy according to presence of severe adhesions*

\begin{tabular}{|c|c|c|c|c|c|c|}
\hline & \multicolumn{3}{|c|}{ With severe adhesions } & \multicolumn{3}{|c|}{ No severe adhesions } \\
\hline & $\begin{array}{l}\text { 2D group } \\
(n=24)\end{array}$ & $\begin{array}{l}\text { 3D group } \\
(n=24)\end{array}$ & $P$ value & $\begin{array}{c}2 D \text { group } \\
(n=14)\end{array}$ & $\begin{array}{l}\text { 3D group } \\
(n=13)\end{array}$ & $P$ value \\
\hline Age of patient, $y$ & $36.0(7.5)$ & $35.4(7.0)$ & 0.751 & $37.5(6.7)$ & $35.9(7.4)$ & 0.566 \\
\hline Body mass index, $\mathrm{kg} / \mathrm{m}^{2}$ & $23.5(4.4)$ & $21.1(2.4)$ & 0.023 & $23.3(4.5)$ & $21.6(2.8)$ & 0.262 \\
\hline Size of ovarian cyst, $\mathrm{cm}$ & $6.1(2.4)$ & $4.7(2.0)$ & 0.029 & $6.1(1.4)$ & $5.7(2.3)$ & 0.615 \\
\hline Bilateral cysts & $7(29.2 \%)$ & $6(25.0 \%)$ & 0.745 & $9(64.3 \%)$ & $9(69.2 \%)$ & 0.785 \\
\hline Surgeon's experience $>5$ years & $12(50.0 \%)$ & $15(58.3 \%)$ & 0.562 & $7(50.0 \%)$ & $6(46.2 \%)$ & 0.842 \\
\hline Blood loss, mL & $43.8(42.0)$ & $44.4(56.6)$ & 0.966 & $74.6(90.3)$ & $83.9(47.4)$ & 0.741 \\
\hline Overall GOALS score & $29.7(5.1)$ & $27.6(4.9)$ & 0.146 & $28.1(5.1)$ & $29.6(3.7)$ & 0.374 \\
\hline Depth perception & $4.3(0.8)$ & $4.0(0.8)$ & 0.159 & $3.7(1.2)$ & $4.4(0.7)$ & \\
\hline Bimanual dexterity & $4.1(0.7)$ & $4.0(0.9)$ & 0.721 & $4.1(0.9)$ & $4.2(0.7)$ & \\
\hline Efficiency & $4.3(1.0)$ & $4.0(0.8)$ & 0.186 & $4.0(1.0)$ & $4.2(0.6)$ & \\
\hline Tissue handling & $4.4(0.8)$ & $3.7(0.8)$ & 0.003 & $4.0(0.7)$ & $4.2(0.8)$ & \\
\hline Autonomy & $4.3(0.9)$ & $4.1(0.9)$ & 0.503 & $4.1(0.7)$ & $3.9(0.8)$ & \\
\hline Duration of cystectomy, min & $90.3(43.1)$ & $77.0(32.1)$ & 0.233 & $93.9(52.0)$ & $127.4(66.6)$ & 0.162 \\
\hline
\end{tabular}

Abbreviations: 2D = two-dimensional; 3D = three-dimensional; GOALS = Global Operative Assessment of Laparoscopic Skills

* Data are shown as mean (standard deviation) or No. (\%) of subjects

\section{Discussion}

Three-dimensional laparoscopy is gaining popularity complex tasks ${ }^{5}$ and in beginners. ${ }^{6,8,14}$ However, in modern gynaecological surgery owing to improved our study was unable to show an improvement in depth perception and spatial orientation compared terms of GOALS score and duration of operation with 2D laparoscopy. Improved effectiveness (Table 2) despite the 3D laparoscopy group having using 3D laparoscopy has been shown extensively a smaller mean ovarian cyst diameter (Table 1 ). This 
finding contradicts a recent meta-analysis that $3 \mathrm{D}$ laparoscopy was associated with shortened surgical time and hospital study, less blood loss, and fewer perioperative complications. ${ }^{15}$

The addition of binocular vision and depth perception in 3D laparoscopy is associated with more frequent adverse effects such as ocular fatigue, nausea, and dizziness. ${ }^{16}$ In the present study, participating surgeons in the 3D group more frequently reported nausea, dizziness, ocular fatigue, and blurring of vision than did those in the 2D group. However, this result may be because the participating surgeons were unfamiliar with 3D images; with experience, this discomfort may be lessened. Maintaining stability of the telescope is of utmost importance during 3D laparoscopy; therefore, familiarity with 3D images is important for assistants to mitigate adverse effects. Furthermore, maintaining an appropriate distance between the screen and the surgeon also alleviates nausea and ocular fatigue. ${ }^{16}$

Previous studies have shown that 3D laparoscopy is beneficial for less experienced surgeons $s^{6,8,14}$ and for any surgeon performing complex tasks. ${ }^{5}$ However, in our subgroup analysis, we were unable to confirm any benefits of $3 \mathrm{D}$ laparoscopy in relation to the experience level of the surgeons. All participating surgeons were much more familiar with 2D laparoscopy and, thus, the difference between groups might simply reflect the surgeon's assessment of what they are used to. This familiarity effect may explain the lower scores in tissue handling and efficiency with 3D laparoscopy attained by the more experienced surgeons.

The surgeon's preference for 2Dlaparoscopy and the heterogeneity of the participating surgeons and patients make the subgroup analyses underpowered and represents a constitute limitation of the present study. The differences in mean diameter of the ovarian cysts and body mass index between the two groups also suggest ineffective randomisation. Other limitations include ineffective randomisation, withdrawal of patients after randomisation, and surgeon's lack of experience with 3D laparoscopy. During data analysis, there were also no controls for possible confounding factors, such as experience of each surgeon with 3D laparoscopy or significant differences in patient characteristics between the groups.

In conclusion, the results show that there is no significant benefit to using 3D laparoscopy for ovarian cystectomy compared with conventional 2D laparoscopy. Moreover, 3D laparoscopy is associated with more frequent adverse effects for surgeons. However, it is possible that more complex procedures, such as those involving laparoscopic suturing and knot tying, might be easier to perform with 3D laparoscopy than with 2D laparoscopy. Therefore, further evaluation of the clinical performance of 3D laparoscopy in operations of different complexities and of surgeons with different experience levels are warranted.

\section{Author contributions}

All authors have made substantial contributions to the concept of this study; acquisition of data; analysis or interpretation of data; drafting of the article; and critical revision for important intellectual content.

\section{Acknowledgement}

We wish to thank Ms Wai-ki Choi for helping in patient recruitment and data collection.

\section{Funding/support}

This research received no specific grant from any funding agency in the public, commercial, or not-for-profit sectors.

\section{Declaration}

The authors have no conflicts of interest to disclose. All authors had full access to the data, contributed to the study, approved the final version for publication, and take responsibility for its accuracy and integrity. The study was presented as oral presentation in the 25th Asian and Oceanic Congress of Obstetrics and Gynaecology, 16 June 2017, Hong Kong.

\section{Ethical approval}

Ethical approval was obtained from the Institutional Review Board of the University of Hong Kong/Hospital Authority Hong Kong West Cluster. Written informed consent was obtained from all participating patients and surgeons. The study was registered with ClinicalTrials.gov (NCT02775344).

\section{References}

1. Storz P, Buess GF, Kunert W, Kirschniak A. 3D HD versus 2D HD: surgical task efficiency in standardised phantom tasks. Surg Endosc 2012;26:1454-60.

2. Lusch A, Bucur PL, Menhadji AD, et al. Evaluation of the impact of three-dimensional vision on laparoscopic performance. J Endourol 2014;28:261-6.

3. Tanagho YS, Andriole GL, Paradis AG, et al. 2D versus $3 \mathrm{D}$ visualization: impact on laparoscopic proficiency using the fundamentals of laparoscopic surgery skill set. J Laparoendosc Adv Surg Tech A 2012;22:865-70.

4. Sørensen SM, Savran MM, Konge L, Bjerrum F. Threedimensional versus two-dimensional vision in laparoscopy: a systematic review. Surg Endosc 2016;30:11-23.

5. Wagner OJ, Hagen M, Kurmann A, Horgan S, Candinas D, Vorburger SA. Three-dimensional vision enhances task performance independently of the surgical method. Surg Endosc 2012;26:2961-8.

6. Cicione A, Autorino R, Breda A, et al. Three-dimensional vs standard laparoscopy: comparative assessment using a validated program for laparoscopic urologic skills. Urology 2013;82:1444-50.

7. Bilgen K, Ustun M, Karakahya M, et al. Comparison of 3D imaging and 2D imaging for performance time of laparoscopic cholecystectomy. Surg Laparosc Endosc Percutan Tech 2013;23:180-3.

8. Fanfani F, Rossitto C, Restaino S, et al. How technology 
can impact surgeon performance: a randomized trial comparing 3-dimensional versus 2-dimensional laparoscopy in gynecology oncology. J Minim Invasive Gynecol 2016;23:810-7.

9. Hong Kong College of Obstetricians and Gynaecologists. Endoscopic surgery: accreditation of gynaecological laparoscopic surgery. Available from: http://www.hkcog. org.hk/hkcog/pages_2_64.html. Accessed 4 Jun 2017.

10. Vassiliou MC, Feldman LS, Andrew CG, et al. A global assessment tool for evaluation of intraoperative laparoscopic skills. Am J Surg 2005;190:107-13.

11. Ko JK, Li RH, Cheung VY. Two-dimensional versus three-dimensional laparoscopy: evaluation of physicians' performance and preference using a pelvic trainer. J Minim Invasive Gynecol 2015;22:421-7.

12. Hulka JF, Omran K, Berger GS. Classification of adnexal adhesions: a proposal and evaluation of its prognostic value. Fertil Steril 1978;30:661-5.

13. Revised American Fertility Society classification of endometriosis: 1985. Fertil Steril 1985;43:351-2.

14. Alaraimi B, El Bakbak W, Sarker S, et al. A randomized prospective study comparing acquisition of laparoscopic skills in three-dimensional (3D) vs. two-dimensional (2D) laparoscopy. World J Surg 2014;38:2746-52.

15. Cheng J, Gao J, Shuai X, Wang G, Tao K. Two-dimensional versus three-dimensional laparoscopy in surgical efficacy: a systematic review and meta-analysis. Oncotarget 2016;7:70979-90.

16. Kunert W, Storz P, Kirschniak A. For 3D laparoscopy: a step toward advanced surgical navigation: how to get maximum benefit from 3D vision. Surg Endosc 2013;27:696-9. 